\title{
Progress, Hotspots and Trends of International Interdisciplinary Education Research in the Past 30 Years - Visualization Analysis of Journal Papers Based on WoS
}

\author{
Wei Lina, Zhang Wei, and Qu Chen
}

\begin{abstract}
In recent years, interdisciplinary education has become the focus of world education reform because of its effective response to building a world-class university. In order to explore the research context of interdisciplinary education, this paper takes the 1988-2018 international interdisciplinary education research literature included in the Web of Science (WOS) database as the research object, combined with scientific map analysis and analysis of classical literature research for international interdisciplinary in the past 30 years. The overall situation, hotspot frontiers and evolutionary characteristics of educational research. The research indicates that the core academic journals that focus on their achievements have not yet been formed in the field of interdisciplinary education research; the core research scholars mainly come from the United States and Northern Europe, which basically form the characteristics of "big center, small diffusion" research institutions; their research focuses on interdisciplinary research. Professional degree setting, interdisciplinary medicine/engineering education, sustainable education, etc.: The research frontier focuses on STEM education, primary and secondary education, and intelligent teaching. Through the traditional literature combing and time zone co-occurrence clustering visualization, the evolutionary characteristics of interdisciplinary education research are summarized as follows: from instrumental interdisciplinary integration research to interdisciplinary thinking cognition research; from single interdisciplinary subject research to multi-subject research; Quantitative research methods are combined with quantitative and qualitative research methods.
\end{abstract}

Index Terms - Interdisciplinary education, research progress, research hotspots, visual analysis.

\section{INTRODUCTION}

Interdisciplinary education is an important support for the continuous growth, evolution and development of disciplines, and is also an indispensable key in the construction of world-class universities and first-class disciplines [1]. In China, along with the promulgation of the "Overall Plan to Promote the Construction of World-Class Universities and First-Class Disciplines", the "double-first-class" construction constitutes the main theme of the current reform and

Manuscript received October 13, 2019; revised December 15, 2019. This research is the phased achievement of the National Natural Science Foundation of China (11724047) and (71750003). The research was funded by the above two projects.

Lina Wei is with Institute of China's Science,Technology and Education Policy, Zhejiang University, China (e-mail: 291702@zju.edu.cn).

Wei Zhang is with School of Public Affairs, Zhejiang University, Hang Zhou, China (e-mail: zhangwei2015@zju.edu.cn).

Qu Chen is with Zhejiang University, Hang Zhou, China (e-mail: 11822025@zju.edu.cn). development of China's higher education. Exploring how to use the key points of the IDE to consolidate the basic engineering of the first-class undergraduate teaching, which is a "double-class" construction, is undoubtedly an era proposition that needs to be studied and solved in front of us [2]. Interdisciplinary education has become the focus of education, but at present, the academic circles have little research on its research hotspots and trends. Based on this, this paper makes a comprehensive review of the progress, research hotspots and frontiers of existing interdisciplinary education research. This paper uses bibliometric methods and information visualization software to quantitatively study and analyze the journal distribution, core authors, classic literature and research hotspots of global interdisciplinary education research, and prospects the global picture of future interdisciplinary education research.not change the font sizes or line spacing to squeeze more text into a limited number of pages. Use italics for emphasis; do not underline.

\section{DATA PROCESSING AND RESEARCH METHODS}

The CiteSpace software developed by Dr. Chen Chaomei from Drexel University in Philadelphia, USA is a visualization software for co-word network analysis and literature citation analysis. Due to its openness and visualization characteristics, it has become the most distinctive and influential in the field of information analysis in recent years. Visual information software [3]. This study uses the software to visualize the knowledge map of international interdisciplinary education literature, aiming to select key information from the database to systematically grasp the research dynamics in this field.

This paper mainly uses the keyword search method, with the core collection of Web of Science as the search source, according to the advanced search $\mathrm{TS}=$ (Interdisciplinary education) in the limited year (1988-2018), the qualified document type (Article) to define the language (English) In the case of the search, a total of 4,529 articles were obtained. The authors used the 4,529 articles of literature data as "records and citations" as the record content, downloaded and saved them in plain text as a file format, and deleted duplicate or undownloadable documents, and finally obtained 4032 valid articles as the book. Sample of the study. The research mainly analyzes the authors, research institutions, keywords and cited documents of 4032 articles. The analysis mainly includes the overall situation analysis of the papers (Journal distribution, core authors, leading countries, etc.), and research hotspots in the field of 
international interdisciplinary education. And trend analysis, knowledge base analysis of interdisciplinary education research [4]. At the same time, this paper also obtained some research data by using Web of Science to analyze the search results online and create citation reports.

\section{ANALYSIS OF THE OVERALL SitUATION OF} INTERNATIONAL INTERDISCIPLINARY EDUCATION RESEARCH

The overall situation refers to the research progress presented by international interdisciplinary education research in various aspects such as journal distribution, core authors, and leading countries. Grasping the overall situation of interdisciplinary education is crucial to outline the research landscape of interdisciplinary education.

\section{A. Distribution of Total Annual Publications}

This paper conducts time statistics on the collected valid texts of 4032 articles, and finds that the number of interdisciplinary education researches is steadily increasing. The development of interdisciplinary education in 1988-2007 is relatively flat. After 2007, interdisciplinary education research has experienced explosive growth.

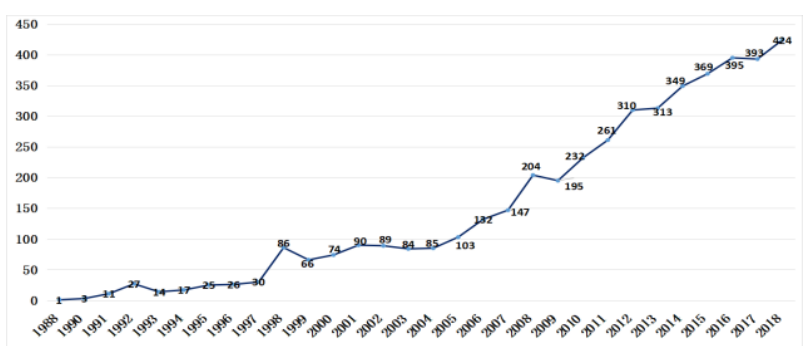

Fig. 1. The number and trend of interdisciplinary education research.

\section{B. Distribution of Core Research Institutions}

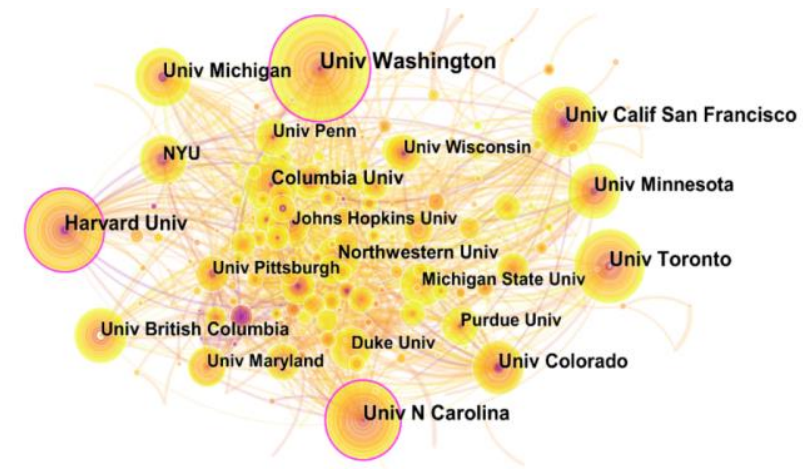

Fig. 2. Knowledge map of interdisciplinary educational research institutions.

The 4032 articles collected in this paper are from 4470 research institutions, of which only 500 research institutes have published more than five documents. The papers published by other institutions are only short-lived and do not form a good interdisciplinary educational research heritage. At present, interdisciplinary education research has formed a distribution model of research institutions with "big center gathering and small center diffusion". The main research institutions in the field of interdisciplinary education research are mainly distributed in Europe and North America, and the interdisciplinary research institutions in the United States occupy the core position. World-class universities represented by the University of Washington, Harvard University, and the University of Michigan have become the main force of interdisciplinary research. In addition, a small number of research institutions have issued large numbers of their own clusters, such as the University of California, Pittsburgh. Both the university and Northwestern University have published more than eight books. The study also found that among Chinese universities, the Hong Kong University of Education and the Chinese University of Hong Kong ranked first in eight publications.

\section{Distribution of Core Journals}

A total of 4,032 papers were classified by source publication, and 2,164 source publications were found. Table I on the next page presents the core publications with more than 20 publications. "Education Science Discipline", "Chemical Education", "Chemical Engineering Education Magazine", "Computer Education", "Medical Education", "Pharmaceutical Education" is the current issue of interdisciplinary education research and the highest citation rate, but there is no specific cross-country in this field. The core journals of the research results of subject education are mostly distributed in the journals of education, engineering and medical education.

TABLE I: DisTRIBUTION OF PUBLICATIONS OF MAJOR SOURCES OF INTERDISCIPLINARY EDUCATION RESEARCH ( $\geq 20$ ARTICLES)

\begin{tabular}{|c|c|c|c|c|c|}
\hline No. & Publication name & $\begin{array}{c}\text { Five-year } \\
\text { influence } \\
\text { factor }\end{array}$ & $\begin{array}{c}\text { Number of } \\
\text { publications }\end{array}$ & Percentage & Total citations \\
\hline 1 & $\begin{array}{c}\text { JOURNAL OF } \\
\text { CHEMICAL } \\
\text { EDUCATION }\end{array}$ & 1.57 & 121 & 2.67 & 669 \\
\hline 2 & $\begin{array}{c}\text { EDUCATION } \\
\text { SCIENTIFIC } \\
\text { DISCIPLINES }\end{array}$ & 4.801 & 105 & 2.32 & 2209 \\
\hline 3 & $\begin{array}{l}\text { INTERNATION } \\
\text { AL JOURNAL } \\
\text { OF } \\
\text { ENGINEERING } \\
\text { EDUCATION }\end{array}$ & 0.663 & 78 & 1.72 & 322 \\
\hline 4 & \begin{tabular}{|} 
AMERICAN \\
JOURNAL OF \\
PHARMACEU \\
TICAL \\
EDUCATION
\end{tabular} & 2.085 & 46 & 1.02 & 563 \\
\hline 5 & $\begin{array}{l}\text { COMPUTERS } \\
\text { EDUCATION }\end{array}$ & 5.568 & 41 & 0.91 & 966 \\
\hline 6 & \begin{tabular}{|l} 
INTERNATION \\
AL JOURNAL \\
OF \\
SUSTAINABIL \\
ITY IN \\
HIGHER \\
EDUCATION
\end{tabular} & 2.443 & 34 & 0.75 & 212 \\
\hline 7 & $\begin{array}{c}\text { EDUCATIONA } \\
\mathrm{L} \\
\text { GERONTOLOG } \\
\mathrm{Y}\end{array}$ & 0.927 & 28 & 0.62 & 125 \\
\hline 8 & $\begin{array}{c}\text { MEDICAL } \\
\text { EDUCATION }\end{array}$ & 4.883 & 27 & 0.60 & 1098 \\
\hline 9 & $\begin{array}{c}\text { IEEE } \\
\text { TRANSACTIO } \\
\text { NS ON } \\
\text { EDUCATION }\end{array}$ & 1.88 & 26 & 0.57 & 252 \\
\hline
\end{tabular}




\begin{tabular}{|c|c|c|c|c|c|}
\hline 10 & $\begin{array}{c}\text { NURSE } \\
\text { EDUCATION } \\
\text { TODAY }\end{array}$ & 2.434 & 23 & 0.51 & 210 \\
\hline 11 & \begin{tabular}{|c|} 
ENVIRONMEN \\
TAL \\
EDUCATION \\
RESEARCH
\end{tabular} & 3.027 & 21 & 0.46 & 131 \\
\hline 12 & \begin{tabular}{|c} 
JOURNAL OF \\
GEOGRAPHY \\
IN HIGHER \\
EDUCATION
\end{tabular} & 1.188 & 21 & 0.46 & 117 \\
\hline 13 & $\begin{array}{l}\text { JOURNAL OF } \\
\text { PROFESSIONA } \\
\text { L ISSUES IN } \\
\text { ENGINEERING } \\
\text { EDUCATION } \\
\text { AND } \\
\text { PRACTICE }\end{array}$ & 2.177 & 20 & 0.44 & 49 \\
\hline
\end{tabular}

\section{Distribution of Core Authors}

The core author is the key figure in laying the foundation of the research field and the backbone of the innovation and development of the discipline. As can be seen from Table II, the core authors of interdisciplinary education are concentrated in the United States, Germany, and Canada, which indicates that the most concentrated research on interdisciplinary education in these countries has the greatest impact on the field.

TABLE II: LEAD AUTHOR OF INTERDISCIPLINARY EDUCATIONAL RESEARCH $(\geq 5)$

\begin{tabular}{|c|c|c|c|c|}
\hline Name & Organization & Articles & Percentage & $\begin{array}{c}\mathrm{H}- \\
\text { Index }\end{array}$ \\
\hline $\begin{array}{c}\text { BORREGO } \\
\mathrm{M}\end{array}$ & $\begin{array}{l}\text { Interdisciplinary Grad Educ Grad } \\
\text { Sch, Fairbanks, AK } 99775 \text { USA. }\end{array}$ & 10 & $0.22 \%$ & 9 \\
\hline $\begin{array}{c}\text { FERRELL } \\
\mathrm{B}\end{array}$ & $\begin{array}{l}\text { Univ Calif Los Angeles, Med Ctr, } \\
\text { Los Angeles, CA } 90024 \text { USA }\end{array}$ & 8 & $0.18 \%$ & 6 \\
\hline JOHN SM & $\begin{array}{l}\text { Univ Osnabruck, Dept Dermatol } \\
\text { Environm Med \& Hlth Theory, } \\
\text { D-49090 Osnabruck, Germany }\end{array}$ & 8 & $0.18 \%$ & 6 \\
\hline SMITH T & $\begin{array}{l}\text { Sheffield Hallam Univ, Sheffield } \\
\text { S10 2BP, S Yorkshire, England }\end{array}$ & 8 & $0.18 \%$ & 5 \\
\hline BEGG MD & $\begin{array}{l}\text { Mailman Sch Publ Hlth, New } \\
\text { York, NY USA }\end{array}$ & 7 & $0.16 \%$ & 5 \\
\hline LEE S & $\begin{array}{c}\text { Univ Texas, Hlth Sci Ctr, Dept } \\
\text { Med, Div Nephrol, San Antonio, } \\
\text { TX } 78229 \text { USA }\end{array}$ & 7 & $0.16 \%$ & 4 \\
\hline $\begin{array}{c}\text { WILLIAM } \\
\text { S B }\end{array}$ & $\begin{array}{l}\text { Monash Univ, Fac Med Nursing \& } \\
\text { Hlth Sci, Dept Community } \\
\text { Emergency Hlth \& Paramed } \\
\text { Practice }\end{array}$ & 7 & $0.16 \%$ & 4 \\
\hline $\begin{array}{c}\text { WULFHOR } \\
\text { ST B }\end{array}$ & $\begin{array}{l}\text { Univ Osnabruck, Dept Dermatol } \\
\text { Environm Med \& Hlth Theory, } \\
\text { D-49090 Osnabruck, Germany }\end{array}$ & 7 & $0.16 \%$ & 6 \\
\hline MARTIN S & $\begin{array}{l}\text { Univ Peruana Cayetano Heredia, } \\
\text { CRONICAS Ctr Excelencia } \\
\text { Enfermedades Cron, Sch Med, } \\
\text { Lima, Peru }\end{array}$ & 6 & $0.132 \%$ & 3 \\
\hline $\begin{array}{l}\text { NEWSWA } \\
\text { NDER LK }\end{array}$ & $\begin{array}{c}\text { Virginia Polytech Inst \& State } \\
\text { Univ, Blacksburg, VA } 24061 \text { USA }\end{array}$ & 6 & $0.132 \%$ & 5 \\
\hline CLARK PG & $\begin{array}{c}\text { Univ Rhode Isl, Providence, RI } \\
\text { 02908 USA }\end{array}$ & 5 & $0.11 \%$ & 4 \\
\hline $\begin{array}{l}\text { CONNOR } \\
\text { DJ }\end{array}$ & $\begin{array}{l}\text { CUNY Hunter Coll, Sch Educ, } \\
\text { New York, NY } 10021 \text { USA }\end{array}$ & 5 & $0.11 \%$ & 4 \\
\hline
\end{tabular}

\begin{tabular}{|c|c|c|c|c|}
\hline \multirow{2}{*}{ JONES C } & $\begin{array}{c}\text { Univ Tasmania, Sch Business, } \\
\text { Australian Innovat \& Res Ctr, } \\
\text { Hobart, Tas, Australia }\end{array}$ & 5 & $0.11 \%$ & 5 \\
\hline $\begin{array}{c}\text { KREITZER } \\
\text { MJ }\end{array}$ & $\begin{array}{c}\text { Univ Minnesota, Sch Nursing, } \\
\text { Minneapolis, MN 55455 USA }\end{array}$ & 5 & $0.11 \%$ & 2 \\
\hline O'ROURK & $\begin{array}{c}\text { Univ Idaho, Dept Philosophy, } \\
\text { E M }\end{array}$ & 5 & $0.11 \%$ & 4 \\
\hline
\end{tabular}

\section{E. Distribution of the Country or Region Where the Author Belongs}

The 4032 articles collected in this paper are from 86 countries/regions, and the articles in the United States and the United Kingdom are the most, accounting for $56.90 \%$ and $6.8 \%$ of the total papers respectively (as shown in Table III on the following page). China has a publishing volume of $1.99 \%$. The main institutions are the Chinese Academy of Sciences, Wuhan University, Peking University, Beijing University of Aeronautics and Astronautics, Shanghai Jiaotong University, Tsinghua University, etc. Hong Kong mainly includes Hong Kong Institute of Education, Hong Kong Polytechnic University, The Chinese University of Hong Kong, and the University of Hong Kong. . The papers produced by different countries and regions are not only different in quantity, but also in quality. From the perspective of the largest reference frequency, the United Kingdom, the United States, Germany, Australia, Canada, Switzerland, and Belgium have greater influence, and the papers of China and France have been cited less frequently. From a central point of view, the articles of the United Kingdom, Sweden, the United States, the Netherlands, and Belgium play a strong role in the node and play a key role in connecting knowledge maps.

TABLE III: MAJOR NATIONAL DISTRIBUTION OF INTERDISCIPLINARY EDUCATION RESEARCH (CENTRAL AND TOP 13 COUNTRIES)

\begin{tabular}{|c|c|c|c|c|c|}
\hline \multirow{2}{*}{ Number } & Country & $\begin{array}{c}\text { Centr } \\
\text { ality }\end{array}$ & Articles & $\begin{array}{c}\text { Percent } \\
\text { age }\end{array}$ & $\begin{array}{c}\text { Maximum } \\
\text { Citation } \\
\text { Frequency }\end{array}$ \\
\hline 1 & Britain & 0.20 & 308 & $6.80 \%$ & 336 \\
\hline 2 & Sweden & 0.14 & 81 & $1.79 \%$ & 186 \\
\hline 3 & U.S.A & 0.12 & 2577 & $56.90 \%$ & 864 \\
\hline 4 & Netherlands & 0.12 & 111 & $2.45 \%$ & 130 \\
\hline 5 & Belgium & 0.12 & 61 & $1.35 \%$ & 209 \\
\hline 6 & Canada & 0.11 & 351 & $7.75 \%$ & 303 \\
\hline 7 & Spain & 0.11 & 88 & $1.94 \%$ & 147 \\
\hline 8 & Portugal & 0.09 & 39 & $0.738 \%$ & 83 \\
\hline 9 & Switzerland & 0.08 & 90 & $1.99 \%$ & 209 \\
\hline 10 & Germany & 0.06 & 233 & $5.15 \%$ & 461 \\
\hline 11 & France & 0.06 & 62 & $1.37 \%$ & 50 \\
\hline 12 & Australia & 0.04 & 258 & $5.70 \%$ & 209 \\
\hline 13 & China & 0 & 90 & $1.99 \%$ & 39 \\
\hline
\end{tabular}

\section{F. Distribution of Major Disciplines}

Table IV lists the distribution of major disciplines of interdisciplinary educational research under the classification of Web of Science. There are two main categories: health care and scientific services, physics, medicine, engineering, chemistry and other traditional disciplines, and environment and ecology, psychology, neuroscience and neurology, education and educational research, education and science. New disciplines of category. In addition, it can be found that 
medicine, engineering and other disciplines with deep foundation are the mainstream of interdisciplinary education research, and new disciplines such as computer science, neuroscience and psychology have gradually occupied the prominence of interdisciplinary education research.

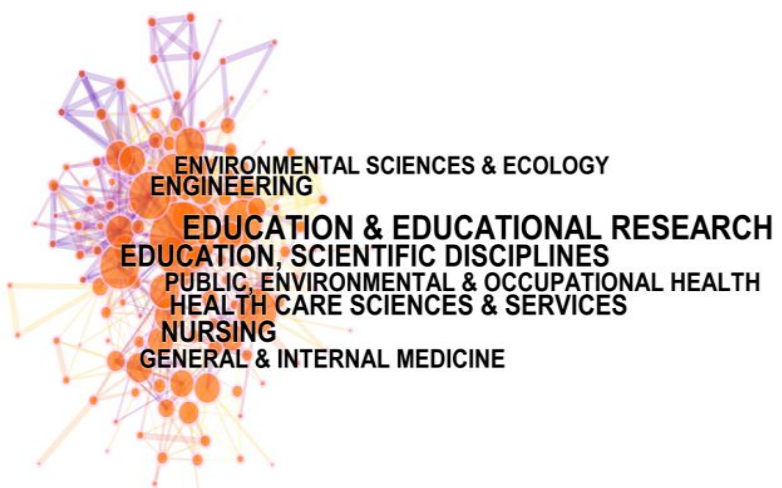

Fig. 3. The distribution of major discipline areas in the research field of interdisciplinary education.

\section{HOT TOPICS AND FRONTIER ANALYSIS OF INTERDISCIPLINARY EDUCATION RESEARCH}

Keyword is very important in academic papers. Keyword clustering can not only retrieve the required literature, but also understand the main content of the article. Therefore, keyword clustering can intuitively reflect the research hotspots and trends in a certain field [5]. In order to quickly grasp the research hotspots and current research situation in the field of interdisciplinary education, this study conducts quantitative investigation and cluster analysis of high-frequency keywords and salient words in the field of interdisciplinary education research. The high-frequency key words in the field of interdisciplinary education are always found to rank first in terms of curriculum, project, interdisciplinary education, teamwork and medical education. In order to further understand the relationship between keywords, this paper analyzed the keyword co-occurrence clustering and clustering superposition of emergent keywords, and further excavated the theme and hotspots of interdisciplinary education research worldwide.

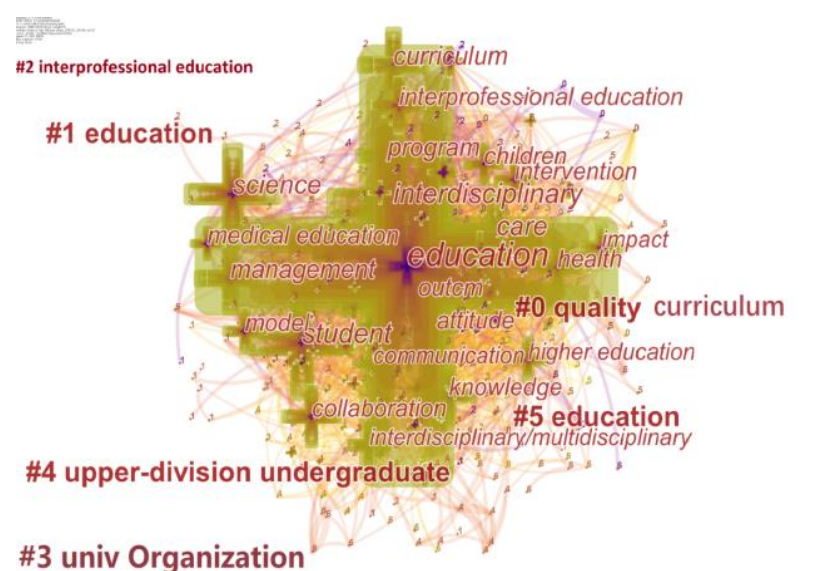

Fig. 4. High-frequency keyword co-occurrence clustering in interdisciplinary education.

TABLE IV: HIGHLIGHTING RATE OF HIGH-FREQUENCY KEYWORDS AND KEYWORDS IN INTERNATIONAL INTERDISCIPLINARY EDUCATION RESEARCH (TOP

\begin{tabular}{|c|c|c|c|c|c|}
\hline \multicolumn{6}{|c|}{ 22) } \\
\hline No. & Frequency & Key Words & No. & Highlighting Words & Highlighting Rate \\
\hline 1 & 904 & education & 1 & education & 13 \\
\hline 2 & 313 & interdisciplinary & 2 & physician & 10.34 \\
\hline 3 & 272 & student & 3 & medical education & 7.09 \\
\hline 4 & 241 & care & 4 & prevalence & 6.24 \\
\hline 5 & 227 & science & 5 & introductory chemistry & 6.77 \\
\hline 6 & 189 & curriculum & 6 & implementation & 5.53 \\
\hline 7 & 173 & management & 7 & training & 5.46 \\
\hline 8 & 159 & program & 8 & graduate education/research & 5.24 \\
\hline 9 & 146 & collaboration & 9 & risk factor & 5.32 \\
\hline 10 & 143 & knowledge & 10 & interdisciplinary project & 5.1 \\
\hline 11 & 137 & health & 11 & integration & 4.99 \\
\hline 12 & 129 & Outcome & 12 & nanotechnology & 4.93 \\
\hline 13 & 129 & Interprofessional education & 13 & survey & 4.9 \\
\hline 14 & 126 & attitude & 14 & graduate education & 4.85 \\
\hline 15 & 125 & model & 15 & interdisciplinary team & 4.76 \\
\hline 16 & 124 & children & 16 & inquiry-based learning & 4.43 \\
\hline 17 & 118 & intervention & 17 & art & 4.31 \\
\hline 18 & 114 & impact & 18 & faculty & 4.05 \\
\hline 19 & 113 & Medical education & 19 & quality improvement & 4.01 \\
\hline 20 & 108 & higher education & 20 & controlled trial & 3.98 \\
\hline 21 & 102 & communication & 21 & interdisciplinary learning & 3.94 \\
\hline 22 & 89 & experience & 22 & creativity & 3.74 \\
\hline
\end{tabular}


interdisciplinary education research, the size and contour value of the clusters can be judged. The main research hotspots in the interdisciplinary education field are cluster 0 , clusters 1 and 2. The research hotspots are concentrated in the following aspect.

1) Interdisciplinary education paradigm change, paying attention to the "student-centered" intelligent teaching model change

From the perspective of high-frequency clustering, the development of intelligence and information age has had a great impact on the learning style and teaching mode of higher education. Under the influence of the global "student-centered" teaching philosophy, higher education institutions are actively exploring how intelligent technology can promote the transformation of teaching methods, educational concepts, and educational situations. While maintaining the "product-oriented" project-based teaching, the problem-centered traditional teaching method, intelligent robot teaching, 3D virtual and other leading new teaching modes have been formed. In the future, universities need to build a multi-dimensional space teaching model to cultivate students' interdisciplinary research and work ability. The exploration and research of new interdisciplinary teaching mode is the hotspot and focus of the future. At the same time, with the development of subject areas such as brain science and cognitive science, computer science, big data, artificial intelligence, new technologies and new methods are emerging, which provides a reference for interdisciplinary education in large-scale and complex problems in education. Scientific methods and technical tools [6].

2) Setting up interdisciplinary professional degrees, cross-disciplinary talent training among doctors and workers has become the research frontier

Establish interdisciplinary degree education and cultivate interdisciplinary doctoral development as a high-frequency hotspot for interdisciplinary education. At present, interdisciplinary education research focuses on clinical medicine and engineering education. From the high-frequency keywords and highlighted keywords, the solution to complex problems in the engineering field requires the joint efforts of interdisciplinary experts. Also in the process of disease prevention, diagnosis and treatment in the medical field, there is an urgent need for interdisciplinary members with different backgrounds. Collaboration can bring medical theory together to clinical practice. At present, the establishment of a doctoral degree for doctoral students in interdisciplinary education is a hot topic. Countries represented by the United States and Germany have established interdisciplinary doctoral degrees to explore a new paradigm for interdisciplinary personnel training. Just like the Vienna University of Technology in Europe, focusing on environmental information cross-disciplinary, a doctoral student college has been set up to set up a multi-disciplinary doctorate in environmental informatics based on different environmental issues to explore a new model of interdisciplinary high-level talent training [7]. At the same time, interdisciplinary talent training pays more attention to students' capacity building and quality improvement. Thought-centered and project-centered education is still an important way to improve the quality of talent training.

3) Focus on the emerging interdisciplinary layout and focus on changes in interdisciplinary teams and interdisciplinary organizations

The rise of interdisciplinary research and interdisciplinary education has spurred changes in the organizational system of higher education. The research on interdisciplinary organizations mainly focuses on case studies and introduces typical cases of the United States, Germany, and European governments in promoting interdisciplinary research and education in universities. High-frequency keywords are teamwork, international cooperation, and national laboratories. Engineering Research Center, Information Technology Center, Science and Technology Center, Materials Center, and Learning Science Center are the representatives. In recent years, the research is based more on the knowledge production model theory of Gibbons, exploring the interdisciplinary organization layout and the best model of university interdisciplinary departments. The keywords such as government, universities, and enterprises frequently appear in such research. At the same time, some scholars have studied a series of organizational supporting policies such as the composition of interdisciplinary research committees, the appointment of interdisciplinary teachers, and the evaluation of interdisciplinary team performance [8].

\section{B. Research Frontier Analysis}

Based on the overall trend of international interdisciplinary education, we can grasp the research knowledge base in this field by analyzing the highly cited classical literature in this field. At the same time, this study uses CiteSpace software to classify interdisciplinary education by using composite network clustering of co-cited articles and terms that refer to these articles, using terminology extracted from topics and abstracts, and terminology with a sudden increase in frequency of occurrence. Research frontiers. According to the time, the size of the cluster and the contour value, it can be judged that the main research frontiers in the interdisciplinary education field are cluster 0 , clusters 2 and 3 (as shown in Table VI, limited to the space where only the main research frontiers are listed. class). From the perspective of clustering, the preliminary research fronts of interdisciplinary education can be analyzed as follows:

1) "Interdisciplinary" assessment becomes the pain point and frontier of interdisciplinary education

The academic research on "interdisciplinary" evaluation has never stopped. Many scholars try to measure the interdisciplinary "interdisciplinary" to adjust the curriculum structure and teaching mode that adapts to the discipline. American scholar Porter is a pioneer in interdisciplinary measurement research. In 2007, Porter et al. classified the subject of Web of Science as the basic unit of analysis, and measured the integration using the two methods of measurement concentration and dispersion in the study [ 9], afterwards, the interdisciplinary integration assessment has aroused widespread concern in the academic community. Although the academic research on interdisciplinary assessment has lasted for ten years, the academic community has great doubts about the measurement and definition of 
"interdisciplinary" and there is no consensus on the evaluation method. The impact of externalities on interdisciplinary evaluation results, the impact of input processes and input time on the measurement of interdisciplinary research, the impact of literature lags and patent citation delays on "interdisciplinary" measurement are the focus of academic debate. The "interdisciplinary" assessment mainly evaluates the level of knowledge integration. Because different subject participants have different organizational models, it is difficult to reach consensus on interdisciplinary education assessment methods. Therefore, how to establish an appropriate evaluation framework and strengthen understanding and respect among experts in interdisciplinary education evaluation and system design and implementation to achieve the goal of promoting interdisciplinary education is the pain point and development front of interdisciplinary education research. .

2) Perceive global change scenarios and emphasize the sustainable development of interdisciplinary education

Interdisciplinary education has a strong Westernism, and the research theme pays special attention to the real problems of Western society. In recent years, the international environmental problems and the aging of the population have become increasingly prominent. These changes have made the research hotspots of interdisciplinary education evolve towards the sustainable development of education. In 2009, the National Academy of Engineering successively issued the "21st Century Challenge" and the "Great Challenge Scholars Program" [10]. The former describes the 14 major engineering challenges faced by human society in the $21 \mathrm{st}$ century, and the latter advocates from the perspective of complex environmental issues. Scholars should "interdisciplinary issues as the center" for interdisciplinary cooperation. At the same time, the European Union introduced the "Europe 2020 Strategy: Achieving Intelligence, Sustainability and Inclusive Growth" [11], and it is expected to guide higher education for sustainable research reform at the national level. Sustainable development has become an important concept of global economic development, and problem-based interdisciplinary education has become an important means of designing and introducing complex environmental issues. Therefore, integrating the concept of sustainable development into the teaching, research and service links of interdisciplinary education is an important task for the development of interdisciplinary education. From the perspective of clustering, the sustainable development of existing interdisciplinary education focuses on the transformation of educational organizations. University organizations are given more rights. The construction of interdisciplinary academies and interdisciplinary environment have become important for the development of sustainable education in universities. the way. In addition, the promulgation of interdisciplinary education programs at the national level is also favored by the development of sustainable education. Respond to major needs, seize the characteristics of endogenous dynamics of information technology, and focus on revealing the law of education in the Internet+ era.

3) In-depth integration of interdisciplinary education and information technology, primary and secondary schools will become pilot reforms for interdisciplinary education In highlighting keyword aggregation, children and preschool education are outstanding in highlighting keyword clustering. STEM education, online online courses, learning science based on brain cognition, and education decision-making based on big data have become the research frontiers of interdisciplinary education. . As the American Academy of Engineering said, STEM education will become an important model for interdisciplinary education, and the future development of interdisciplinary education will also pay more attention to the penetration of grassroots education [12]. In the inter-disciplinary education at the grassroots level, interactive "touch" (information touch) tools such as interactive robots and educational information skills have become the frontiers of research. Due to the particularity of the grassroots education audience, the academic community is paying more and more attention to how to integrate interdisciplinary education into younger children with a variety of interesting teaching methods. At the same time, educational psychology such as metacognitive development and neuro-education development is also receiving more and more attention from the higher education community. The concept of "interdisciplinary education" has been extended, and the education community has begun to think about how to proceed from the essence of education and gradually pay attention to the development of deep interdisciplinary thinking. In addition, with the development of subject areas such as brain science and cognitive science, computer science, big data, artificial intelligence, new technologies and new methods are emerging, providing a reference for large-scale and complex problems in interdisciplinary research education. Methods and technical tools.

\section{RESEARCH CHARACTERISTICS OF INTERNATIONAL INTERDISCIPLINARY EDUCATION}

At present, there are few scholars in China to sort out the context and literature of interdisciplinary education. Most of the existing literature on interdisciplinary education focuses on case studies and personnel training mode. It is even rarer to use CiteSpace to visualize the analysis of interdisciplinary education. In this study, the basic situation, research frontiers and theoretical basis of international interdisciplinary education research in the past 30 years from 1988 to 2018 are visually analyzed, which provides a unique perspective for the development of international interdisciplinary research, and also provides a useful reference for the development of interdisciplinary education in China.

\section{A. North America and Europe Are the Main Research Subjects and Institutions of Interdisciplinary Education Research}

From the basic situation, the western countries occupy an absolute advantage in international interdisciplinary education research, while China has a small voice in the field of interdisciplinary education research. North American and European countries, led by the United States, Germany and Australia, are outstanding in the high cited classical literature and publications. These countries have basically laid the foundation for interdisciplinary education research. In 
addition, the University of Washington, Harvard and the University of California in the United States have become the important positions of interdisciplinary education research, leading the development of interdisciplinary education. Obviously, the United States is a leader and leader in interdisciplinary educational research.

B. The Outline of Interdisciplinary Educational Research Has Initially Taken Shape, But There Are Differences in the Focus of Attention between China and the West

From the perspective of research content and subject of interdisciplinary education, a framework for analyzing the elements of teachers, students and training methods has been preliminarily formed. At present, the international interdisciplinary education research focuses on the discipline horizon (mainly engineering and medicine). Most of the issues concerned are relatively micro-level, such as how to form interdisciplinary teams, typical cases of interdisciplinary medical centers, the analysis of an interdisciplinary course, the construction of a macro-interdisciplinary curriculum system framework, the employment of interdisciplinary teacher teams, and interdisciplinary science. How to construct the academic circle has not yet formed a unified understanding. On the contrary, most of the research on interdisciplinary education in China focuses on the macro-research of the construction and operation of interdisciplinary organization mechanism and the construction of interdisciplinary time platform. There is a big gap between the two. The international interdisciplinary education research represented by the United States and Europe is "bottom-up" endogenous research, and the grass-roots interdisciplinary team pays more attention to the focus of society. China's interdisciplinary education research is "top-down" exogenous research, and its effective implementation subject is universities and countries. It expects to create a set of applicable mechanisms and rules from the organizational point of view.

\section{Empirical Study on the Preference of International Interdisciplinary Educational Research}

From the perspective of research methods, international interdisciplinary education research mostly focuses on empirical research, and tends to explore the relationship between variables and variables. The impact of interdisciplinary education model on students' learning performance is the focus of scholars' attention. On the contrary, domestic research basically does not use empirical research, focusing on foreign excellent case studies. Scholars try to seek effective reference from cases for China. However, the applicability analysis of its case is rare. Similarly. Both international and domestic interdisciplinary educational research lack theoretical support, which is the pain and difficulty in this field.

\section{Interdisciplinary Educational Groups Need to Be Further Expanded}

From the research frontier, the development of information technology and complex social problems have a great impact on interdisciplinary education. The extension of the concept of "interdisciplinary" has been expanded. The existing interdisciplinary education is no longer limited to the influence of teaching mode and Thinking on it, but gradually pays attention to the development of deep interdisciplinary thinking. At the same time, the quality crisis of higher education also stimulates the thinking of quality improvement in interdisciplinary education. The construction of students' interdisciplinary ability has become the frontier of interdisciplinary education research. It can be predicted that the research centered on interdisciplinary thinking and interdisciplinary ability will become the frontier of future research. In addition, traditional interdisciplinary education fields, such as medicine and engineering, have formed mature and reproducible models, and subsequent cross-cutting of agriculture and industry, literature and industry, and medical workers will also become future research trends.

\section{CONCLUSION}

From the analysis results, many problems in interdisciplinary education still can not be solved by existing research: measurement of interdisciplinary nature, analytical framework of interdisciplinary education research, organizational change of interdisciplinary education, and international cooperation of interdisciplinary education. There is still a lot of room for development of interdisciplinary education research. Of course, this study also has some limitations. This study only chooses the WOS database from 1988 to 2018 as the data source of the literature. Future research can further enrich the data sources, and can be further analyzed and compared with domestic research. In addition, CiteSpace software can only analyze the theme, abstract and key words of literature. If we want to understand the theory and process of interdisciplinary education, we need to read classical literature intensively to grasp the key of interdisciplinary education research accurately.

\section{CONFLICT OF INTEREST}

The authors declare no conflict of interest".

\section{AUTHOR CONTRIBUTIONS}

L.W. conceived and designed the experiments. L.W. and Z.W. analyzed the data and wrote the original manuscript, Q.C. provided advice and revised the manuscript. All of the authors have read and approved the final manuscript submitted to the editor.

\section{ACKNOWLEDGMENT}

This research is the phased achievement of the National Natural Science Foundation of China (11724047) and (71750003). The research was funded by the above two projects.

\section{REFERENCES}

[1] J. C. Huang, Contemporary Educational Science, 2018, no. 06, pp. 21-25.

[2] Y. X. Wang, "Interdisciplinary education: The only way to establish first-class undergraduate teaching in Chinese universities — Take 
environmental undergraduate teaching as an example," China Higher Education Research, 2016, no. 06, pp. 17-24.

[3] Y. Chen et al., Principles and Applications of Citation Spatial Analysis, Beijing: Science Press, 2014, p. 46.

[4] C. M. Chen et al., "Methodological functions of knowledge map of Chen Yue," CiteSpace, Scientific Research, 2015, vol. 33, no. 02, pp. 242-253.

[5] J. Wang et al., "Hotspots and trends of big data research on education based on Catespace," Modern Education Technology, 2016, vol. 26, no. 02 , pp. 5-13.

[6] J. L. Zhang, "Intelligence: The inevitable trend of educational development and change in intelligent society schools," Educational Exploration, 2018, no. 1.

[7] Official website of Vienna University of Technology [EB/OL]. (2019). [Online]. Available: https://www.tuwien.ac.at/

[8] E. L. Larson et al., "Building interdisciplinary research models: A didactic course to prepare interdisciplinary scholars and faculty," Clinical and Translational Science, 2011, vol. 4, no. 1, pp. 38-41.

[9] A. L. Porter, A. S. Cohen, and J. D. Roessneretal, "Measuring research interdisciplinary narity," Scientometrics, vol. 72, no. 1, 2007, pp. $117-147$

[10] W. Wu et al., "Comments on the implementation of the Great Challenge Scholar Program, a new strategy for training top engineers in the United States," Education Development Research, 2010, vol. 30, no. 23, pp. 63-68.

[11] M. Zou, "Educational development concept of the European 2020 strategy," Higher Education in China, 2015, no. 5, pp. 61-63.

[12] Progress report on coordinating federal science, technology, engineering, and mathematics (STEM) Education. The White House. [Online]. Available: https://www.whitehouse.gov/sites/default/files/microsites/ostp/stembu dgets upplementfy17final.pdf. 2016
Copyright ( $\odot 2020$ by the authors. This is an open access article distributed under the Creative Commons Attribution License which permits unrestricted use, distribution, and reproduction in any medium, provided the original work is properly cited (CC BY 4.0).

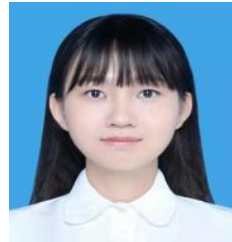

Lina Wei is a doctoral students majoring in education, economics and management, Institute of China's Science,Technology and Education Policy, Zhejiang University.

Her educational background:

2017.3, Doctor candidate of Educational Economy and Engineering, Zhejiang University (Directly studying for a Ph.D., because of my interest in engineering education research, I entered the school half a year earlier than the Ph.D. program)

2013.9-2017.6, B.S. in Administrative management, Department of Public Administration, Dalian Maritime University.

Academic Experience:

2018.01-present, Participant. China Engineering Talent 2030 Forecast:The Development and Trends of China's Engineering Talents, Sponsored by Chinese Academy of Engineering.

2017.11-present, Participant. Study on the Selection Mechanism and Organization Mode of Educational Science Strategic Research Topics, Sponsored by National Natural Science Foundation of China.

2017.09-present, Participant. Classification, Stratification, and Staged Engineering Talents Training System: Research on Reengineering of Engineering Education System in China, Sponsored by Chinese Academy of Engineering.

2017.03-2017.10, Participant. The Trend of Engineering Education Reform in the Background of Made in China 2025, Sponsored by Chinese Academy of Engineering. 